Garrido Sánchez, V. (2020): La epopeya dañada: patología familiar en As I Lay Dying. Cultura, Lenguaje y Representación, Vol. XXIII, 83-95 ISSN $1697-7750 \cdot$ e-ISSN 2340-4981

DOI: http://dx.doi.org/10.6035/clr.2020.23.5

\title{
La epopeya dañada: patología familiar en As I Lay Dying
}

The damaged epic: family pathology in As I Lay Dying

VIOLETA GARRIDO SÁNCHEZ

UNIVERSITAT DE BARCELONA

Artículo recibido el / Article received: 2019-10-13

Artículo aceptado el / Article accepted: 2020-02-11

RESUMEN: El objetivo de este artículo es dilucidar mediante qué estrategias narrativas se construyen las relaciones familiares patológicas de una de las novelas más notables de William Faulkner, la cual resulta ser una expresión literaria representativa de la complejidad que adquieren las relaciones afectivas a partir de la modernidad, asunto que no ha perdido vigencia. Combinando una lectura narratológica y una lectura psicológica, el análisis aquí propuesto examina las motivaciones, problemáticas y contradicciones de los personajes de As I Lay Dying en relación al particular contexto histórico en el que están insertos, tan típico en Faulkner, marcado por la carencia, la represión y la imposición de roles sociales estrictos, algo que marca fuertemente su subjetividad. En última instancia, el artículo se cuestiona también en qué medida la disfuncionalidad emocional de la que estos hacen gala tiene un origen social que radica en la institución misma de la familia como estructura básica de socialización.

Palabras clave: Faulkner, Bundren, familia, afecto, patología, disfuncional.

ABSTRACT: The aim of this paper is to elucidate the narrative strategies that build the pathological family relationships in one of William Faulkner's most remarkable novels, this being a representative literary expression of the increased complexity in affective relationships after modernity, an outstanding issue still today. By combining a narratological interpretation and a psychological interpretation, the proposed analysis examines the motivations, problems and contradictions of the characters of As I Lay Dying in connection with the particular historical context they live in. That context is characterized by lack, repression and the imposition of strict social roles, which strongly influences their subjectivity, as Faulkner typically shows. Ultimately, the paper also investigates the social origin of the emotional dysfunctionality defining the personality of every character and its entrenchment in the family institution as a basic socialization structure.

Key words: Faulkner, Bundren, family, affection, pathology, dysfunctional. 


\section{INTRODUCCIÓN}

Si tenemos que hacer caso a Heidegger y tras el Dasein subyace impertérrito el Sein zum Tode (ser para la muerte), la procesión con el cadáver de Addie Bundren hasta Jefferson por parte de una grotesca comitiva familiar es el inexorable y martilleante memento mori de dicha condición trágica. La oscilación constante de As I Lay Dying y sus personajes entre lo heroico y lo ridículo revela, de acuerdo con Eagleton (2011: 115), esa «conciencia carnavalesca» de las criaturas divididas que, al emerger en el seno mismo de unos acontecimientos funestos, implica tanto una crítica al heroísmo como un ejemplo de él. La tosquedad que presentan las personalidades creadas por Faulkner no es, pues, una simple apología de lo antiheroico, sino que se vincula a una configuración especial de la epicidad — que resulta, por cierto, bastante democratizadora — por la cual el periplo sobre el que se escribe se dirige hacia el abismo porque no puede ser de otra manera, y sus protagonistas, lejos de encarnar con elitismo valores nobles y dignos, son el producto contradictorio de un mundo en decadencia. Podría decirse que As I Lay Dying es, haciendo uso del término que emplea Adorno en Minima moralia, y recordando que el título de la obra proviene de un parlamento de Agamenón a Ulises, una odisea «dañada», una epopeya sobre lo miserable de las relaciones humanas, pero que, por el hecho de dirigirse desconsoladamente al horror, lo afronta y, precisamente así, «afirma la posibilidad de lo mejor» (Adorno, 1987: 22).

La profunda discordancia entre esencia y apariencia, que es en sí misma un asunto de reflexión plenamente modernista alentado por aquellos a quienes Ricoeur apodó «filósofos de la sospecha», alcanza cualquier intersticio de la realidad, incluida la familia. Y, como es habitual en el Faulkner productor de ese lugar polifacético y metafórico (pero universal) llamado Sur, la familia es la institución social en base a la cual se erige esta obra hasta cierto punto coral. En As I Lay Dying, tras la apariencia de intenso sacrificio y abnegación altruista que supone emprender un complicado viaje con medios limitados para cumplir la última voluntad de una madre que acaba de expirar, se halla, recónditamente ubicada, una esencia mucho más cruda caracterizada por una dolorosa conflictividad intrafamiliar que es casi inherente a la propia estructuración del dispositivo familiar, sustentado sobre principios jerárquicos y coactivos tremendamente influyentes en el desarrollo psíquico de los sujetos. El linaje Bundren representa con una perfección prototípica eso que Roudinesco (2004: 21) denomina «familia mutilada», hecha de heridas íntimas, violencias silenciosas, y recuerdos reprimidos, y que ya no es, como antaño, una alianza destinada a asegurar la transmisión de un patrimonio, pues incorpora lógicas afectivas complejas y potencialmente patológicas. En las páginas que siguen vamos a examinar en qué medida y con qué estrategias formales se retratan esas relaciones de hostilidad o de afecto disfuncional que han sido institucionalizadas en y a través de la familia. En primer lugar, haremos un repaso de carácter narratológico por las diferentes funciones narrativas que adquieren los personajes de la novela, con objeto de revelar la lógica interna de la obra. En segundo lugar, nos centraremos en las desviaciones o carencias que presentan las figuras materna y paterna en relación a la norma hegemónica. Finalmente, el último apartado estará dedicado a explicar cómo afrontan el duelo los miembros de la familia.

\section{NOMBRE DE APARTADO EN MAYÚSCULAS Y NEGRITA SIN PUNTO CON SALTO}

La construcción de As I Lay Dying sigue los preceptos de lo que podría llamarse «cubismo verbal»: los quince narradores autodiegéticos (fallecidos incluidos) que toman la palabra 
a lo largo de los cincuenta y nueve capítulos comportan un cruzamiento polifónico de voces que ofrece al lector, gracias al stream of consciousness o monólogo interior, la visión subjetiva de cada uno (y, de este modo, es el lenguaje lo que posibilita el desarrollo de una identidad propia en cada personaje). La presencia permanente del discurso inmediato, como prefiere designarlo Genette, refuerza al máximo la ilusión de mímesis, puesto que los personajes hablan desde sí mismos sin injerencias ni mediaciones ${ }^{1}$. Y, sin embargo, es posible distinguir entre ellos un muy sutil reparto de las funciones de telling y showing - o, para decirlo de nuevo con Genette, de narración (diégesis) y exposición (mímesis) — que obedece a la carga trágica que Faulkner deposita en el seno familiar. Por lo general, los monólogos interiores de una buena parte de los personajes exteriores a la familia (fundamentalmente Vernon Tull, Samson, Armstid y Moseley, pero también Cora Tull o Peabody) operan en cierto modo activando el telling, porque aportan mucha información sobre las peripecias clave de la historia: Tull es quien relata la muerte y el velatorio de Addie, la rotura de su puente y el accidentado cruce del río; Samson explica el retroceso inicial hacia el puente de Tull; Armstid informa sobre la pierna rota de Cash y la compra de un nuevo tiro, y Moseley revela el embarazo y las tentativas de aborto de Dewey Dell. Son, en definitiva, quienes se hacen cargo del relato y hacen avanzar la acción mediante mecanismos narrativos explícitos.

Por su parte, los monólogos miembros de la familia (a excepción de Darl, que como veremos tiene un estatuto diferenciado) obedecen a dinámicas narcisistas en las que cada cual se afana por explicarse: en efecto, todos ellos justifican sus comportamientos y se eximen de responsabilidad, mostrándose impotentes e incapaces de sobreponerse a la adversidad (o sencillamente de comprender lo que pasa a su alrededor, en el caso de Vardaman), en un movimiento que recuerda remotamente a la captatio benevolentiae clásica, pero que en realidad encubre un fuerte complejo de culpa por los peligros a los que queda expuesto el cadáver materno durante la travesía y previamente - desde la accidentada construcción del ataúd, que mantiene el cuerpo al aire libre más de lo debido. Las voces de estos personajes sirven más al showing de los contenidos íntimos particulares que al tratamiento del material narrativo propiamente dicho (por eso sus pensamientos se presentan desordenados, como efusiones del inconsciente) $)^{2} \mathrm{y}$, en el fondo, se valen de un discurso marcadamente egoísta que se hace notorio por la delectación con que cada uno de ellos aborda recurrentemente sus preocupaciones individuales (las cuales demuestran ser, para ellos, al menos en principio, cualitativamente superiores a la que suscita el fallecimiento de Addie): Anse está obsesionado con sus dientes, Dewey Dell piensa en su embarazo, Cash cavila sobre el ataúd desnivelado, Vardaman no soporta la presencia de los cuervos y fantasea con el tren de juguete, Jewel no se separa de su caballo, etc.

La posición y el encaje del monólogo de Addie Bundren, no obstante, obedecen a razones distintas de naturaleza estructural que revelan asimismo la importancia nuclear de su carga discursiva, de la que nos ocuparemos extensamente en el próximo apartado. $\mathrm{Si}$ bien es cierto que todos los personajes despliegan habitualmente movimientos

\footnotetext{
${ }^{1}$ Para entender mejor el funcionamiento de la enunciación discursiva de los personajes de la novela conviene recordar, a propósito, la aportación de Benveniste (1966: 88-89) respecto al desdoblamiento del yo que se produce en los monólogos interiores: «Con frecuencia el yo locutor es el único que habla, pero el yo receptor permanece presente; su presencia es necesaria y suficiente para volver significativa la enunciación del yo locutor. Algunas veces el yo receptor aparece por medio de una objeción, una pregunta, una duda, un exabrupto».

${ }^{2}$ Es decir, como ha señalado Ross (1979: 303), quien insiste en distinguir en la novela una voz mimética y una voz «textual», en sus secciones narrativas, los personajes de la familia se expresan como personajes y no como narradores.
} 
analépticos y digresivos, sus monólogos se ordenan de forma más o menos cronológica (que es, quizás, la única manera de poder intercalar las dinámicas propias del showing y el telling descritas hace un momento sin desorientar excesivamente al lector). Por el contrario, la intervención de Addie tiene lugar cuando ya se ha producido su fallecimiento, lo cual no sólo supone una visible infracción de ciertas leyes lógicas pues los muertos no hablan - que, por otra parte, la idiosincrasia del pacto ficcional inherente a toda novela consigue camuflar exitosamente. Incluso aunque se tratase de recuerdos previos a su muerte reproducidos más tarde y no de una voz simultánea al momento de la lectura, su localización y su misma existencia constituyen una declaración sobre las pretensiones del relato que, por su contenido, es capaz de trascender las instancias de la muerte. Ello explica la importante significación que adquiere el cuerpo, ininteligible desde el punto de vista lingüístico (pero cuyo malestar solo puede expresarse, paradójicamente, a través del lenguaje) y que opera a veces desde parámetros imprevisibles e imprimiendo una huella afectiva que perdura más allá de la desaparición física del mismo; por eso mismo, a pesar de lo hostil que pueda ser el ambiente, el cuerpo actúa como el principal exponente de la pulsión de vida. Es el trabajo faulkneriano de la técnica narrativa al completo lo que permite concebir la mente y el cuerpo como una dualidad inseparable y de influencias mutuas cuyo resquebrajamiento entrañará inequívocamente un peligro para cualquier sujeto.

De esta manera, la dicotomía conformada por los dos tipos de voces narrativas que hemos descrito - de la cual Addie queda, como se ha dicho, en cierto modo excluida al constituir un elemento ternario particular - faculta, por un lado, un progreso diegético muy consistente en el plano de lo meramente factual (telling) y, por otro, la paulatina mostración de las soterradas rencillas familiares y la disparidad de caracteres (showing). Esto último, justamente, se vuelve funcional a la exhibición, continua en toda la novela, de que existe algo connaturalmente quebrantado en las relaciones constitutivas de la familia. Incluso Darl — narrador en el que, debido a la cantidad de intervenciones, la utilización de una sintaxis más compleja salpicada de lirismo, la atracción por cuestiones metafísicas y la tendencia a la analepsis, pueden reconocerse ciertas marcas autorales faulknerianas - desempeña también, al participar de ambos modos narrativos, un papel sustancial a la hora de destapar los traumas que acosan a sus parientes y a sí mismo. Con esta decisión técnica, Faulkner instaura una división de las labores narrativas por medio de la cual cada monólogo está determinado por las motivaciones ulteriores de cada hablante, evitando así la homogeneización de la comunidad de voces. Sea como fuere, parece claro que el monólogo interior opera a través del método «laissez faire, laissez parler» (Clancier, 1973: 13), que permite, a medida que se descubre el carácter del personaje, descifrar lapsus, comportamientos neuróticos o histéricos, actos fallidos..., esto es, la verdad profunda que no se enuncia verbalmente de otro modo.

\section{MATERNIDAD TOTÉMICA, PATERNIDAD AUSENTE}

La recia personalidad de Addie Bundren en parte cimenta o legitima la idiosincrasia presuntamente totémica con que es investida como figura materna del clan, lo que le permite asimismo actuar como soporte para la cohesión social del grupo. Y una hipótesis entre otras sería que por eso, porque la matriz de la historia no reside tanto en la pura crónica de una muerte anunciada ya en las primeras páginas como en un conjunto de metas individuales para cuya consecución el cuerpo yaciente es un subterfugio, el cadáver resiste casi incólume los múltiples atentados que se producen contra su integridad. A decir verdad, este yo aglutinador de la familia que es Addie se ha conformado defensivamente y concentra en su experiencia vital la infelicidad de la existencia, cuyo máximo exponente 
es la esterilidad del lenguaje: en efecto, el inevitable truncamiento comunicativo es un síntoma de la imposibilidad de realización personal en un mundo que define a las mujeres por su función reproductiva y las conmina a asumir un rol pasivo en el entramado familiar y social. El monólogo de Addie, además de constituir, a su modo, una síntesis de la preocupación modernista sobre la esencia del lenguaje (según la cual las palabras no serían más que un-dispositivo de falsificación de lo real, algo que parece ser una fijación en Faulkner y que presupone la conciencia saussuriana de la arbitrariedad del signo lingüístico), es la ilustración de una rebelión polimórfica de carácter pre-edípico (por cuanto destila una fuerte añoranza por el periodo en el que no existen diferencias entre el self y el mundo).

Lo que en un principio parece un embate contra las insuficiencias del sistema lingüístico — si hemos de atender a la severidad de las palabras de Addie: «That was when I learned that words are no good; that words dont ever fit even what they are trying to say at» (Faulkner, 1985: 171) ${ }^{3}$ —, se nos va revelando progresivamente como una protesta más amplia y afinada que abarca tanto resentimientos estrictamente personales como cuestionamientos de carácter colectivo sobre la división sexual del trabajo que impera en su sociedad. La insatisfacción que padece por las condiciones materiales de su vida la conduce ya en su juventud a desarrollar, cuando es profesora, un comportamiento sádico contra sus alumnos con el que sublima la frustración y la rabia. El afán de satisfacer su pulsión sexual la arrastra a aceptar la petición de matrimonio de Anse, momento a partir del cual establece una clara relación causal entre dicho compromiso y la consecuente y esperada evasión de esa situación laboral asfixiante; la conjunción so de la oración So I took Anse, repetida en dos ocasiones (pp. 170 y 171) y referida al matrimonio, es reveladora en ese aspecto ${ }^{4}$. No obstante, Addie descubre muy pronto que el embarazo y la maternidad son el resultado natural y terrible de la culminación del deseo sexual. Lejos de realizarse a través de la maternidad — puesto que, de algún modo, esta implica una regresión a aquello que odiaba-, Addie percibe con ella el horror de una existencia en la que se la priva de la capacidad de tomar decisiones y, por tanto, también de su subjetividad.

También muy pronto, Addie comprende que la maternidad la tuvo que inventar «someone that had never had the fear» (p. 157), fórmula perifrástica que parece referirse al hombre, y que, en las condiciones histórico-sociales en las que ella vive, implica una negación o una invasión de la sexualidad femenina y un sometimiento al control masculino. El pertinaz rechazo a la maternidad - que Addie explicita con su «I did not ask for them» (p. 174) - conlleva pues la negación de la familia y de sus lógicas afectivas convencionales; dicha negación se materializa en una frialdad afectiva y comunicativa de Addie para con sus allegados, ligada a una visión radicalmente pesimista del mundo preñada de ethos calvinista. Ante una imposición tal, Addie se subleva nuevamente cometiendo adulterio con el reverendo Withfield, gracias al cual recupera momentáneamente su libertad y concibe a Jewel, el único vástago verdaderamente

\footnotetext{
${ }^{3}$ Con el fin de evitar reiteraciones excesivas, de ahora en adelante las citas textuales de la novela, cuya edición ya ha sido indicada, se referenciarán señalando solamente la página de la que se extraen.

${ }^{4}$ La sensual descripción que hace Addie de la naturaleza salvaje por la que pasea tras salir de la escuela «with the water bubbling up and away and the sun slanting quiet in the trees and the quiet smelling of damp and rotting leaves and new earth» (p. 169) — o que percibe durante la noche — «lying in bed at night, with the wild geese going north and their honking coming» (p. 170) - es, simbólicamente, la manifestación del propio deseo sexual; por eso «in the early spring it was worst», hasta el punto de que «Sometimes I thought I could not bear it» (p. 170), donde it funciona como pronombre del deseo sexual irrefrenable.
} 
querido (como sugiere su nombre, que recrea lo que es valioso por definición ${ }^{5}$ ) por cuanto es fruto de la infidelidad en tanto que refutación del contrato de monogamia obligatoria que es el matrimonio - elemento éste último que deviene, no se olvide, la conditio sine qua non de la familia. La conexión especial con Jewel acaba diluyéndose - la madre es sustituida por un caballo- $-\mathrm{y}$, acaso impulsada por una culpa motivada por la infidelidad cometida, Addie pretende compensar a Anse concibiendo a Dewey Dell y a Vardaman, cuyos nacimientos ratifican definitivamente que el sufrimiento es para ella la experiencia definitoria de la feminidad: «I gave Anse Dewey Dell to negative Jewel. Then I gave him Vardaman to replace the child I had robbed him of» (p. 176).

El hecho de que Addie muestra unas dinámicas de resistencia singulares frente a la hegemonía patriarcal es algo que ya ha sido largamente argumentado por Clarke (1994), Bergman (1996) o Hewson (2000), entre otros. Con todo, convendría evitar desde el principio una visión limitada y simplista que eluda el hecho capital de que el personaje (y, por consiguiente, las relaciones que este alimenta) exterioriza su rebeldía de manera profundamente incoherente, haciendo uso de las armas limitadas de las que dispone a su alrededor, entre las que figura su propia condición de madre y esposa. En su monólogo Addie Bundren, repudiando su condición reproductiva, repudia el sistema familiar patriarcal en su conjunto; pero a la vez no puede dejar de sostenerlo y de ampararlo con su mera existencia; no consigue renunciar por completo a ejercer como figura materna aunque sea defectuosamente, y en esa contradicción abierta reposa una herida: la transmisión a su descendencia de una desafección que a la vez la sostiene y la define como sujeto ${ }^{6}$. De modo que el tótem Addie - esa fuerza superyoica casi sobrenatural y profundamente respetada que está en las conciencias de todos los personajes incitándoles a culminar la acción - bien podría ser un ente construido por los suyos siguiendo una lógica de fetichización que compense las carencias afectivas de la Addie real, y que por tanto tampoco garantiza una respuesta afectiva enteramente sincera por parte de quien lo venera (de hecho, por ejemplo, muy pocas veces se la llama madre).

En este sentido, si bien es cierto que el «speech act» de Addie es cuantitativamente menor si se toma en consideración el conjunto de la novela y la participación del resto de personajes, su presencia se atestigua mediante un «creative act» (Clarke, 1994: 21) muy particular: son los cinco actos de procreación de Addie — su incursión (problemática) en la maternidad - los que, a la larga, generan la condición de posibilidad de los actos lingüísticos del resto de personajes, que quedan recogidos en la novela en forma de monólogos interiores; así, el texto que aquí estudiamos - cuya totalidad es el acto lingüístico más voluminoso - acaba convirtiéndose, simbólicamente, en otro hijo de Addie. Con todo, ni siquiera la vehemente impugnación del lenguaje que se observa en Addie - cuyo eco resuena en Darl y en Dewey Dell, quienes se comunican entre sí sin necesidad de usar palabras, o en Vardaman, quien, como su madre, tiene problemas para nombrar - consigue suspender uno de los aspectos principales de la novela, referido en el apartado anterior: el juego y entrecruzamiento de voces. La posición de Addie, lejos de negar la centralidad del lenguaje, supone en realidad, como ya hemos mencionado, una interesante apertura hacia el cuerpo y su campo sensorial entendidos, desde un punto de

\footnotetext{
${ }^{5}$ En efecto, no deja de ser curioso que Jewel sea el único nombre que Addie escoge personalmente. Respecto a Cash y a Darl, en cambio, se expresa en sentido opuesto, insistiendo en la idea de que los nombres y las etiquetas son incapaces de definir correctamente el mundo: «It doesn't matter. It doesn't matter what they call them» (p. 159).

${ }^{6}$ Respecto a la naturaleza contradictoria — a la vez contestataria y legitimadora — de la actuación de Addie, Fowler (1989: 115) ha sugerido que, en As I Lay Dying, Faulkner reescribe el mito dominante de nuestra cultura, es decir, la identificación mítica del cuerpo de la madre con las ideas de castración y muerte, pero dejando hablar a la madre muerta como agente, que es también una manera de subvertir el mito.
} 
vista semiótico, como otros textos que revelan información constantemente. Sólo así puede entenderse, por ejemplo, la resistencia que presenta el cadáver de Addie a deteriorarse o disolverse siguiendo el mandato de las leyes físicas, o la renuncia de los Bundren a enterrarlo antes de tiempo. La presencia material del cuerpo de Addie niega así la división ontológica entre la vida y la muerte y, en última instancia, «impedes the literal and symbolic transformation of mother to earth» (Clarke, 1994: 40), lo que implica, de nuevo, una negación hasta las últimas consecuencias de la maternidad y de los mitos que se le asocian.

Por su parte, la personalidad rudimentaria y pusilánime de Anse contrasta vivamente con el perfil materno: la apatía y la desidia con que afronta su situación y su obstinación por asegurar su sustento material lo configuran ante todo como un individuo avejentado y primario, también físicamente. Anse se atiene al código de honor de la sociedad sureña tradicional y profesa un marcado pesimismo indiscutiblemente ligado a esa célebre metáfora que equipara el discurrir de la vida terrenal con el tránsito por un tortuoso «valle de lágrimas» cuya recompensa se obtiene en la vida celestial: «Every man will be equal there and it will be taken from them that have and give to them that have not by the Lord» (p. 65). En este sentido, Anse sería el perfecto representante de lo que Hewson (2000: 554) denomina «male inaction», una ontología anclada en la pasividad que se contrapone a la «female activity» de Addie y de los hijos, y desde la que, en última instancia, resuena la filosofía agorera del padre de Addie: «the reason for living was to get ready to stay dead a long time» (p. 114). Su constante propensión a compadecerse de sí mismo y de la desdicha de su sino hace pensar que Anse experimenta una neurosis de destino por la cual su existencia estaría subjetivamente caracterizada por una fatalidad externa al individuo en forma de un retorno periódico de acontecimientos desgraciados, a los que termina por someterse abúlicamente. A pesar de tener menos estatus y menos credibilidad (y también menos riqueza) que los representantes masculinos de su entorno, Anse siempre está dispuesto a solicitar la caridad de los otros, quizás porque «he enjoys having the attention that comes with being a widower» (Butchart, 2015). Paradójicamente, pese a su miserable aspecto y su desventura, la razón de su éxito personal —al final consigue lo que quiere: su dentadura, y de paso una nueva esposaes que cuenta con la habilidad de usar con cada cual el tono emocional adecuado: piadoso y respetuoso con Tull cuando tienen que utilizar su puente para cruzar el río, y autocompasivo y autoritario con Dewey Dell cuando quiere para sí los diez dólares con los que ella pretende costear la interrupción de su embarazo, por ejemplo (Hannon, 2015: 17).

Contrariamente a lo que podría esperarse, Anse no ejerce propiamente como figura paterna en tanto que no transmite a sus hijos ningún ideal del yo congruente en el que estos puedan reconocerse y definirse- y, de hecho, posiblemente la ausencia de autoridad efectiva que él representa es el motivo por el que su criterio es sistemáticamente desdeñado por parte de sus hijos (a juzgar por la cantidad de veces en que Anse, ante las actividades de éstos, pide, sin éxito, «respeto» por el cuerpo y la voluntad de Addie). No en balde, su rasgo más característico es el egoísmo, que se traduce en la preocupación por mantener los modales y cumplir la palabra dada a su esposa hasta el punto de arriesgar su propia vida en un trayecto plagado de peligros (también para sus hijos: recordemos que Jewel pierde su caballo, Cash la pierna, Dewey Dell el dinero y Darl la libertad). Ello hace presuponer que abriga un hondo cariño por su mujer, pero, en realidad, su praxis posterior le desmiente totalmente (en cuanto le es posible y sin elaborar el duelo, reemplaza a Addie por otra Mrs. Bundren de la que volverá a depender). Así pues, la indolencia inicial del personaje se va disolviendo al perseguir el propio interés en lo que éste tiene de pulsional: la insistencia en ponerse una nueva dentadura - cosa que 
precisamente sólo se vislumbra como posible gracias a la muerte de Addie, que permite el desplazamiento a Jefferson - va indisolublemente unida a la satisfacción de las necesidades fisiológicas asociadas a la comida, por la que es incluso capaz de sacrificar los proyectos vitales de sus hijos. El hecho de que dirija toda su energía libidinal hacia el propio yo convierte a Anse en un ser extremadamente narcisista y por tanto contemplativo y holgazán en lo que se refiere a la organización del viaje y a la resolución de los problemas, además de avaro y desconsiderado con los suyos (Butchart, 2015). En vista de lo que hemos examinado, se hace patente que ambos miembros de la pareja Bundren son impelidos a actuar en base a la experimentación de una ardua lucha interna entre el impulso erótico y el impulso tanático.

\section{DUELO Y AFECTO}

Las dificultades mostradas por todos los miembros de la familia para expresarse de forma mínimamente operativa, a las que ya hemos aludido en los apartados anteriores, influyen enormemente en la gestión del duelo y son otro indicio de la disfuncionalidad afectiva que los caracteriza. Clarke (1994: 39-40) sostiene que los Bundren intentan mitigar el impacto de la muerte de Addie no a través de una utilización locuaz del lenguaje - como sí hacen, por ejemplo, los hermanos Compson en unos monólogos absolutamente desmesurados con los que palian la ausencia de Caddy-, sino fácticamente en el plano de los hechos y, fundamentalmente, mediante símbolos. Es decir, la energía libidinal proyectada hacia la madre se transfiere y queda sublimada en el plano objetal. Incapaces de articular lingüísticamente sus sentimientos, se resisten a aceptar que la madre no tiene ya ninguna presencia literal - lo que implica la negación de la muerte en sí. Por ello, elaboran un entramado simbólico a base de objetos o animales por medio del cual la madre resulta reemplazada figurativamente: para Cash, el ataúd que tan cuidadosamente construye deviene un emblema de la madre, y el gramófono que anhela y consigue al final, una prolongación del cordón umbilical (Catchings, 2014: 26); las funciones del caballo son para Jewel un claro sustituto de las funciones maternas (no por casualidad señala Darl perspicazmente que «Jewel's mother is a horse» [p. 89]); Vardaman no es capaz de procesar racionalmente la muerte de su madre y comunica en axiomas simples su incomprensión de las relaciones identitarias, transformándolas de este modo en correspondencias más accesibles — «My mother is a fish», repite incesantementesustitución que se verá a su vez reemplazada por el tren de juguete y por las bananas que le ofrece Dewey Dell, con las que distrae el dolor de su pérdida.

Dewey Dell, que había asumido, por estar cuidándola, la partida de la madre en el momento exacto de su muerte - y que además comparte con ella la condición de género-, no siente la necesidad de reemplazarla simbólicamente, pero tampoco consigue comunicar verbalmente sus pensamientos y emociones: permanece habitualmente en silencio y no es capaz de hablar abiertamente ni de su embarazo ni de la eventualidad de abortarlo. De todas formas, su situación de embarazada parece entrañar para ella una «crisis of embodiment» (Bollinger, 2015: 436) en la que, de manera traumática y por repetición, está recreando la experiencia de su madre. El embarazo no deseado de Dewey Dell y sus intentos por interrumpirlo supondrían una especie de reiteración del acercamiento problemático a la maternidad que era propio de su madre, con la diferencia de que Dewey Dell no cuenta con las poderosas armas discursivas de Addie: los monólogos de la hija, escasos, no consiguen elaborar tan refinadamente la insatisfacción de su condición. Así, la violación que sufre en su búsqueda de auxilio repite nuevamente el patrón materno: más que confirmar su habilidad para concebir, el embarazo comporta la pérdida del control sobre su vida y sobre su cuerpo, lo que, unido al rechazo a la propia 
sexualidad, se convierte en un signo de deshumanización. Prueba de ello es la manera en que la describe Darl, reduciéndola a la condición de mero fragmento de un cuerpo: «(...) a leg coming long from beneath her tightening dress: that lever which moves the world; one of that caliper which measures the length and breadth of life» (p. 91). Resulta interesante en este sentido el comentario semántico de Kovesdy (2010: 262-263) a propósito de su nombre, que evoca la idea de una sexualidad naciente y desenvuelta: «Dewey sounds like dewy, which refers to something that is "moist with or as if with dew". A dell refers to "a small secluded wooded valley". Dewey Dell then suggests "a fresh morning - and virginal genitalia"». La interpretación subsecuente es que la hija también se rebela furibundamente contra el patriarcado, aunque de manera distinta a como lo hace la madre: cuando, por ejemplo, rechaza cocinar pescado y en su lugar le ofrece a Anse unos grelos (turnip greens) para comer no sólo está desdeñando el mandato patriarcal de encargarse de las tareas domésticas, sino que, teniendo en cuenta que Vardaman vincula simbólicamente a su madre con un pez, al no ofrecerle a Anse el cuerpo de Addie como sustento, Dewey Dell esquiva y desafía la idea subyacente: el sacrificio del cuerpo femenino para ponerlo al servicio de los deseos y las necesidades masculinas, que es la piedra de toque de la ideología patriarcal.

No obstante, el sistema simbólico de sustitución resulta ser un fracaso, puesto que los objetos que lo sustentan acaban perdiéndose, rompiéndose o sacrificándose a lo largo del viaje; ningún proceso de figuración consigue pues desplazar por completo a la madre, ningún objeto podrá conservar su cuerpo eternamente. Con esta articulación fallida del sistema sustitutorio, Faulkner acomete en As I Lay Dying una modernización exitosa de lo que, según Irigaray (1981), es el mito fundacional de la cultura occidental: el asesinato de la madre (y no del padre, como sostuviera en cambio Freud en Tótem y tabú). Por todo ello, la travesía hacia Jefferson acaba siendo para los hijos una experiencia de formación vital, con lo que la novela deviene una suerte de Bildungsroman macabro del que cada uno de ellos extrae lecciones vinculadas a su propio curso madurativo. Este tránsito a la edad adulta es pues un peregrinaje alegórico sumamente penoso, porque comporta la volatilización forzosa de los anómalos vínculos maternos y el aprendizaje de una nueva relación con el propio cuerpo (elementos ambos que comportan una reconfiguración del espacio afectivo de cada cual), sin carecer por ello de coordenadas geográficas concretas, puesto que se produce en el transcurso de un desplazamiento hacia la capital del condado.

Parece entonces que el viaje supone una prolongación indefinida de esos obstáculos que dificultan la adquisición de bienestar, y es también el diagnóstico definitivo de que la familia es una institución estructuralmente fallida. El entierro de Addie Bundren, la conclusión lógica que se espera tras tantas páginas manteniendo la tensión narrativa $-\mathrm{y}$ que es también la conclusión experiencial que los hijos necesitan para asumir definitivamente la muerte de la madre-, apenas se recrea, pues es significativamente eclipsado por la pelea familiar que termina con Darl siendo conducido a Jackson para su internamiento. Este episodio representa a su vez la irrupción expresa del resentimiento mutuo acumulado. El fermento de dicho rencor es perceptible ya en la gestión del duelo que lleva a cabo cada uno de los hijos de Addie, que, como hemos intentado mostrar, es, cuanto menos, singular en cada caso. Dicha singularidad atiende tanto a la disimilitud de caracteres como a esos conflictos que están latentes entre ellos. En la medida en que la madre era esa «figura de consenso» que mantenía contenida la hostilidad, su desaparición es el desencadenante de la liberación del odio colectivo reprimido.

A Jewel, si exceptuamos un único monólogo (como es el caso de Addie, sintomáticamente) en el que expresa una animadversión generalizada hacia el resto de 
personajes ${ }^{7}$, lo conocemos casi exclusivamente través de los ojos de Darl, lo cual brinda al lector una perspectiva bastante parcial del enfrentamiento que los opone. Darl, que por sus dotes observadoras tiene una capacidad extraordinaria para inferir ciertos sucesos subrepticios - sin ir más lejos, sabe que Dewey Dell está embarazada y se comunica «en clave» con ella al respecto-, intuye que Jewel no es hijo de Anse («Jewel, I say, Who was your father, Jewel?» [p. 195]) y, como sabe también que es el único hijo verdaderamente querido por Addie, lo rechaza al verlo como el negativo deseado de sí mismo. Sin embargo, según Palliser (1986: 559) Darl no posee ninguna clarividencia excepcional, sino que se conduce por un fuerte sentido de la predestinación (como Addie) que le permite predecir de forma muy precisa el comportamiento de su familia. De hecho, si Darl contase con una habilidad adivinatoria extraordinaria-habría anticipado la emboscada de la que es víctima en Jefferson y que tiene por objeto conducirlo al asilo de Jackson para, justamente, desposeerlo por completo de la legitimidad de su palabra. Al contrario que Addie, quien rehúsa los engaños del lenguaje y aspira a afrontar la existencia desde la vivencia corporal - aunque sin éxito, como atestigua su experiencia de la maternidad - Darl, en tanto que narrador dominante, tiene una relación mucho más estrecha con el lenguaje y se caracteriza por ser especialmente elocuente. Pero, al atribuírsele socialmente el estatuto de loco, enajenado o demente (la condición necesaria para que pueda ser ingresado en el asilo), queda automáticamente excluido de la esfera discursiva. Foucault explica que «en un sentido estricto, la palabra del loco no existía» puesto que se la consideraba fruto de la ingenuidad o del irracionalismo propio de la locura (Foucault, 1992: 13). Así también Darl acaba siendo silenciado y su persona reducida a un cuerpo desautonomizado que es posible inmovilizar, transportar y encerrar contra su voluntad. Su reclusión en el asilo poco parece tener que ver con su estado mental; más que una decisión altruista tomada por los familiares, sería una medida punitiva y ejemplarizante por la amenaza que la despreocupación que Darl manifiesta hacia la propiedad privada (materializada en una serie de conductas destructivas) representa para la comunidad rural en la que está inserto (Atkinson, 2006: 187).

En otro orden de cosas, y volviendo a la esfera afectiva, para Darl, como decíamos antes, su hermano Jewel parece reactivar constantemente el trauma del abandono materno (Lacan, 1978: 59). Este sentimiento de desamparo afectivo («I cannot love my mother because I have no mother» [p. 95]) desemboca en una crisis de identidad que persigue al personaje hasta abocarlo a un final calamitoso: la disociación total de su personalidad en el camino hacia el manicomio. El proceso comienza con un cuestionamiento progresivo de su propia naturaleza ontológica y genealógica y culmina cuando se autorreferencia directamente en tercera persona ${ }^{8}$. La inestabilidad psicológica de Darl vendría a ser una marca de su diferencia, que en términos políticos puede entenderse como la consecuencia de su inadecuación al sistema normativo de género. En efecto, Darl se encuentra en un

\footnotetext{
${ }^{7}$ La inquina de Jewel contra quien perturba la tranquilidad de Addie y su fijación por aislarse con ella de ese ambiente molesto — «It would just be me and her (...)» (p. 24), dice reveladoramente hacia el final del monólogo - delatan su fuerte complejo edípico.

${ }^{8}$ En una conversación con Vardaman, Darl describe su identidad tal y como él la entiende (plural, múltiple): «(... "I know it", Darl said. "That's why I am not is. Are is too many for one women to foal"» (Faulkner, 1984: 101). Bollinger (2015: 434 y 437) sostiene que el motivo por el que Darl presenta este trastorno disociativo de raíces traumáticas tiene que ver, probablemente, con que ha servido como soldado en la Primera Guerra Mundial. La información de que Darl ha estado «in France at the war» (p. 189) la ofrece hacia el final de la novela precisamente una de las personalidades disociadas de Darl cuando este habla consigo mismo.

El descentramiento identitario de Darl se encuentra también, aunque revestido de actitud infantil, en Vardaman, quien tiene que recordarse constantemente el rol que cumplen los demás para situarse a sí mismo: «Cash is my brother», «Jewel is my brother», «Darl is my brother», etc.
} 
estado liminal en el que ni desempeña las funciones de varón sustentador porque se resiste a contraer matrimonio, ni tampoco es estrictamente un trabajador manual valioso desde el punto de vista de la productividad capitalista, ya que lo que lo singulariza frente a su comunidad es un elevado intelectualismo (Southard, 2013: 50).

Las leves alianzas internas que desgajan el núcleo familiar en dos facciones con intereses afectivos antitéticos se dilucidan a partir del incendio del granero de Gillespie ${ }^{9}$. Dicha división también podría ser la representación tangible de un enfrentamiento simbólico entre Anse y Addie: Jewel y Cash conspiran contra Darl —el elemento más disruptivo de la familia porque exterioriza y lleva al extremo los conflictos al permitir la liberación de las fuerzas del inconsciente-, con la sutil oposición de Dewey Dell y, en menor medida, de Vardaman. Como ha sugerido Azevedo (2014: 91), Jewel y Cash, los únicos que contribuyen materialmente a cumplir el último anhelo de Addie (ya sea construyendo el ataúd o salvándolo del hundimiento o de las llamas), viven en una relación cómplice con la madre, que los considera como sus hijos frente a Darl, Dewey Dell y Vardaman, quienes son vistos como los hijos de Anse y estarían acompañando el féretro por motivos puramente egoístas. No es casual, en este sentido, que la presencia narrativa de Cash - que por lo general había sido muy fragmentaria (hasta el punto de que parte de sus propias argumentaciones quedan incompletas) y se había centrado en cuestiones meramente técnicas relativas a la disposición del ataúd- se acentúe hacia el final, a partir de la desaparición de Darl, como si la exclusión de su hermano constituyese para él una liberación. En cualquier caso, el odio colectivo que suscita Darl se explica porque todos los miembros de la familia ven amenazadas su identidad y su autonomía por el «excesivo» conocimiento que Darl posee (y que guarda para sí) sobre las relaciones profundas que rigen el microcosmos del que forman parte (Bollinger, 2015: 454).

En realidad, como sostiene Clarke (1994: 38), las diferencias afectivas que establece Addie con respecto a sus hijos tienen que ver, por sutiles que estas puedan parecer, con su experiencia personal con la sexualidad, que como hemos visto está inextricablemente unida a la maternidad. En efecto, si al inicio Addie concibe la sexualidad como una oportunidad de escapar de la impositiva esfera del discurso lingüístico, con los años se va convirtiendo en una vivencia degradante por su carácter repetitivo. Al principio, Addie siente que su unión con Cash puede trascender felizmente los límites del lenguaje («Cash did not need to say it [love] to me nor I to him» [p. 158]), pero a partir de su segundo embarazo, se percata de que también la sexualidad sucumbe a las trampas del lenguaje: «I realized that I had been tricked by words older than Anse or love» (p. 158-159).

\section{CONCLUSIONES}

La lectura de As I Lay Dying pone de manifiesto la importancia que tiene en la arquitectura del discurso narrativo la peculiar disposición de los monólogos interiores. Si a Addie y a Jewel Faulkner no les otorga la palabra en la misma medida en que se la concede a los demás personajes es porque solo la ausencia revela la importancia de la presencia, justo como sucede, por ejemplo, en The Sound and the Fury, donde Caddy, aunque no disponga de ningún monólogo propio, se erige como una especie de energía

\footnotetext{
${ }^{9}$ Cabe precisar el carácter crucial que reviste este episodio, por cuanto revela la intención de Darl de detener desesperadamente, en lo que sería un típico mecanismo de defensa, el daño emocional que le está causando el viaje familiar; o quizá también, al pretender deshacerse literalmente del cuerpo de la madre por medio del incendio, expresa su rechazo tanto a la sacralización de la corporeidad como a participar del sistema simbólico que persigue su conservación; o, a la inversa, en ausencia de objeto simbólico sustitutorio, su desesperada necesidad de tomar posesión de Addie incinerando su cuerpo (Fowler, 1989: 121).
} 
ubicua que no cesa de influir en el resto de miembros de su familia. Ambas obras no solo establecen una dicotomía paradójica entre la ausencia y la presencia de la corporeidad femenina y de su lenguaje, sino que también recogen los intentos paralelos de los hombres por lidiar a través o a pesar del lenguaje con la ausencia (a veces simbólica y a veces real) de la figura materna (Clarke, 1994: 19). En virtud de lo analizado en el presente artículo, resulta asimismo obvio que los personajes femeninos de Faulkner traen a primer plano una carnalidad particularmente grotesca y de fatales consecuencias.

La fijación del autor por destacar el poder del lenguaje y las consecuencias terribles de un uso inapropiado del mismo, por diseñar un dramatis personae emocionalmente intrincado y por retratar la familia como una fuerza telúrica de la que es imposible escapar se puede relacionar, a la postre, con el «mito personal» del escritor, ese «fantasma persistente» que presiona durante la actividad creadora para hacerla incurrir una y otra vez en determinadas situaciones, algo que el psicocrítico Charles Mauron (1963) denomina metáforas obsesivas. Lo que se desprende del universo faulkneriano es el sentido catastrófico de un presente en donde, como señalaba con brillantez Sartre (1947: 66), no existe realmente la posibilidad del porvenir, sino solo la evocación del pasado como espacio de conflicto que determina brutalmente el ahora de la narración. En la novela, el cumplimiento del objetivo que define la historia - enterrar a Addie en Jefferson - no garantiza ni siquiera mínimamente la subversión del statu quo, sino más bien al contrario, pues, a nivel estructural y aunque algunos personajes hayan desaparecido, implica la reanudación de las relaciones sociales y afectivas casi en el mismo punto en que se detuvieron cuando dio comienzo la desgracia inaugural de la obra. La ausencia de progresión —o, para decirlo de nuevo como Sartre (1947: 67), la existencia de una «depresión» en términos temporales - forma parte del ordenamiento de la temporalidad que cabe esperar del marco histórico-social en el que Faulkner quiere introducir al lector: el capitalismo agrario y atrasado, humanamente lacerante, del sur estadounidense, causa última del desequilibrio psíquico y emocional de sus habitantes. En un contexto deliberadamente «arcaico-mítico», los personajes son voces insurrectas que fracasan en su aspiración a dejarse oír, atestiguando así el carácter indómito de la naturaleza humana, la cual normalmente queda cohibida y sepultada por la omnipotencia de las construcciones sociales y sus convenciones adyacentes, entre las que por supuesto se encuentra la familia (que es, por lo demás, un espacio afectivamente contradictorio y lleno de fallas).

\section{REFERENCIAS BIBLIOGRÁFICAS}

Adorno, Theodor W. 1987. Minima moralia. Reflexiones desde la vida dañada. Madrid: Taurus.

Atkinson, Ted. 2006. Faulkner and the Great Depression: Aesthetics, Ideology, and Cultural Politics. Athens: University of Georgia Press.

Azevedo, Carlos. 2014. «Do Modernismo em William Faulkner: As I Lay Dying». En Estudos em homenagem a Margarida Llosa, ed. Ana Luísa Amaral. Porto: Faculdade de Letras da Universidade do Porto, 71-97.

Benveniste, Émile. 1999. «El aparato formal de la enunciación». En Problemas de lingüistica general, II. Madrid: Siglo XXI, pp. 82-91.

Bergman, Jill. 1996. "“This was the answer to it": Sexuality and Maternity in As I Lay Dying». Mississippi Quarterly, 49 (3): 393-407.

Bollinger, Laurel. 2015. "“Are is too many for one woman to foal”: Embodied Cognition in As I Lay Dying». Texas Studies in Literature and Language, 57 (4): 433-463. 
Butchart, Liam C. 2015. «Death, Mourning and Human Selfishness: Faulkner's As I Lay Dying Through a Freudian Lens». PSYART: A Hyperlink Journal for the Psychological Study of the Arts. Available at http://psyartjournal.com/article/show/butchartdeath_mourning_and_human_selfishness_fau

Catchings, Libby. 2014. «Elegy, Effigy: Alchemy and the Displacement of Lament in As I Lay Dying». The Faulkner Journal, 28 (2): 25-38.

Clancier, Anne. 1973. Pschanalyse et critique littéraire. París: Privat.

Clarke, Deborah. 1994. Robbing the Mother. Women in Faulkner. Jackson: University Press of Mississippi.

Eagleton, Terry. 2011. Dulce violencia. La idea de lo trágico. Madrid: Trotta.

Faulkner, William. 1985. As I Lay Dying. Nueva York: Vintage International.

Foucault, Michel. 1992. El orden del discurso. Buenos Aires: Tusquets.

Fowler, Doreen. 1989. «Matricide and Mother's Revenge: As I Lay Dying». The Faulkner Journal, 4 (1): 113-125.

Hannon, Charles. 2015. «The Function of Function Words in William Faulkner's As I Lay Dying». The Faulkner Journal, 29 (1): 3-21.

Hewson, Marc. 2000. «"My children were of me alone”: Maternal Influence in Faulkner's As I Lay Dying». Mississippi Quarterly, 53 (4): 551-67.

Irigaray, Luce. 1981. Le Corps-à-corps avec la mère. París: Pleine Lune.

Kovesdy, Joe. 2010. «Dewey Dell in Faulkner's As I Lay Dying». The Explicator, 68 (4): 261-263.

Lacan, Jacques. 1978. La familia. Barcelona: Editorial Argonauta.

Mauron, Charles. 1963. Des métaphores obsédantes au mythe personnel. París: Corti.

Palliser, Charles. 1986. «Predestination and Freedom in As I Lay Dying». American Literature, 58 (4): 577-573.

Ross, Stephen M. 1979. "“Voice" in Narrative Texts: The Example of As I Lay Dying». PMLA, 94 (2): 300-310.

Roudinesco, Elisabeth. 2004. La familia en desorden. Barcelona: Anagrama.

Sartre, Jean-Paul. 1947. "À propos de "Le bruit et la fureur": La temporalité chez Faulkner» en Situations, I (pp. 65-75). París: Gallimard.

Southard, Marybeth. 2013. "“Aint None Of Us Pure Crazy”: Queering Madness in As I Lay Dying». The Faulkner Journal, 27 (1): 47-63. 